\title{
CONSTRUCTION OF SITE DEPENDENT DESIGN SPECTRA
}

\author{
N. Mostaghel* and G. Ahmadi* *
}

\section{ABSTRACT}

A method for construction of smooth site dependent design response spectra is proposed. The simplified procedure for obtaining the site dependent spectra is described. Some comparisons with the response spectra of actual earthquakes are carried out and good agreements are observed.

Comparison with the Newmark's spectra and the Regulatory Guide 1.60 spectra are also presented.

\section{INTRODUCTION}

An excellent review of the methods for constructing design response spectra is provided by Werner (1). Site independent spectra were first introduced by Housner (2) in the late fifties. Since then several other site independent spectra have been developed such as those of NewmarkHall (3), Mohraz-Hall-Newmark (4) and Newmark-Blume-Kapur (5), which are the basis for the current R.G. 1.60 (6).

The studies of Hayashi et al (7), Seed et al (8) and Mohraz (9) show that the soil conditions at a site affect the shape of the response spectra significantly. In order to consider the local soil condition, an ensemble of spectra from the records obtained at stations whose seismological, geological and local soil characteristics nearly represent those of the site are selected. Then, ensemble mean and mean plus standard deviation spectra are constructed. The investigations of (7-9) show that the normalized spectral values for a firm deposit are, in general, lower than those for a soft deposit in the high period region of the spectra and vice versa for the low period region of the spectra. In an alternative technique which is known as "site response analysis" (1), an ensemble of representative subsurface motions are selected and fed to certain mathematical models of the site soil deposits and the output is statistically analyzed to obtain response spectra $(10-17)$.

Recently, Mostaghel and Ahmadi (18) developed a technique for construction of smooth site dependent design spectra which only requires the knowledge of the characteristic site period and the peak ground acceleration.

In this work a simplified procedure for construction of the site dependent smooth spectra as developed in (18) is presented. Some comparisons with the spectra of actual earthquake records are carried out and good agreements are observed. Also comparisons are made with the Newmark spectra (19) and the Regulatory Guide 1.60 spectra (6), and the deficiencies

*Professor, Department of Civil Engineering, Utah University, Salt Lake City, Utah 34112 , U.S.A.

**Visiting Professor, Department of Mechanical Engineering, The University of Calgary, Calgary, Alberta T2N IN4, Canada.

BULLETIN OF THE NEW ZEALAND NATIONAL SOCIETY FOR EARTHOUAKE ENGINEERING, VOL. 14, NO. 4, DECEMBER 1981 of the site independent spectra are pointed out.

\section{PROCEDURE FOR CONSTRUCTION OF SITE DEPENDENT SPECTRA}

In (18) based on several mathematical bounds developed on the magnitude of the response spectra in various frequency ranges and estimation of several relevant parameters, a method for the determination of the site dependent spectra for a site with given site period and peak ground acceleration is established. Here, a simplified procedure for construction of the site dependent spectra as developed in (18) is presented.

According to (18) a site dependent smooth spectra as shown in figure 1 is completely specified if the cocrdinates of seven points ABCDEFG are known.

Suppose $\mathrm{T}_{\mathrm{V}}$ is the predominant site period and $a$ is the peak ground acceleration. The natural periods of various control points then are given by

$$
\begin{aligned}
& \mathrm{T}_{\mathrm{A}}=\mathrm{T}_{\mathrm{V}^{\prime}} \\
& \mathrm{T}_{\mathrm{B}}=4 / \mathrm{T}_{\mathrm{V}^{\prime}} \\
& \mathrm{T}_{\mathrm{C}}=\mathrm{T}_{\mathrm{V}} / 3, \\
& \mathrm{~T}_{\mathrm{D}}=3 \mathrm{~T}_{\mathrm{B}}=12 / \mathrm{T}_{\mathrm{v}^{\prime}} \\
& \mathrm{T}_{\mathrm{E}}=30, \\
& \mathrm{~T}_{\mathrm{F}}=\mathrm{T}_{\mathrm{V}} / 10, \\
& \mathrm{~T}_{\mathrm{G}}=0.03 .
\end{aligned}
$$

All the natural periods are in seconds. The amplitudes of the response spectra at various control points are then given by $\mathrm{S}_{\mathrm{V}}\left(\xi, \mathrm{T}_{\mathrm{A}}\right)=\left(\frac{\mathrm{aT} \mathrm{V}}{2 \pi}\right) \mathrm{N}\left(1-\mathrm{e}^{-100 \xi)^{\frac{1}{2}}}\right.$,

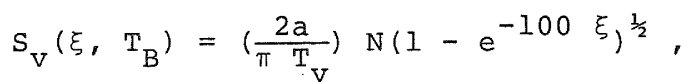

$S_{v}\left(\xi, T_{C}\right)=\left(\frac{a T_{v}}{2 \pi}\right) \frac{N}{3}$

$S_{V}\left(\xi, T_{D}\right)=\left(\frac{a T_{v}}{2 \pi}\right) \frac{N}{3}$,

where $\xi$ is the damping coefficient, and the parameter $\mathrm{N}$ is defined by $\mathrm{N}=(1+2 \xi)\left(\frac{0.2}{\xi}\right)^{\frac{1}{2}}$ for $\xi>0.005$. 
The values of $\mathrm{N}$ and $\mathrm{N}\left(1-\mathrm{e}^{-100 \xi)^{\frac{1}{2}}}\right.$ for various values of damping coefficients are listed in table I. (A comprehensive derivation and discussion of equations (.1) - (6) is provided in (18)).

Table I Values of parameters for several values of damping coefficients

\begin{tabular}{|c|c|c|}
\hline$\xi \circ$ & $N$ & $N\left(1-e^{-100 \xi)^{\frac{1}{2}}}\right.$ \\
\hline 0.5 & 6.388 & 4.007 \\
1 & 4.562 & 3.627 \\
2 & 3.289 & 3.058 \\
5 & 2.200 & 2.193 \\
10 & 1.697 & 1.697 \\
20 & 1.400 & 1.40 \\
\hline
\end{tabular}

It is clear that when the amplitudes of the response spectra of points A, B, C and $D$ are known, the rest of the spectral curve can be completed trivially. The line $\mathrm{DE}$ is a constant displacement line, and the line $C F$ is a constant acceleration line. Point $G$ has an acceleration response equal to that of the ground.

In figure 1 , the smooth site dependent response spectra are plotted for a ground acceleration of $0.3 \mathrm{~g}$ and a site period of $\mathrm{T}_{\mathrm{V}}=.66 \mathrm{sec}$ for several values of damping coefficients. It may be noted that for damping larger than $2 \%$ critical, points $A$, $C$ and $F$ are along the same straight line; similarly points $B, D$ and $E$ are along $a$ straight line.

Figure 2 shows the site dependent spectra for peak ground acceleration of $0.3 \mathrm{~g}$, damping coefficient of $0.5 \%$ and predominant site periods of $1.5,1$ and 0.5 seconds. The natural period $1.5 \mathrm{sec}$ corresponds to a relatively soft site, and $0.5 \mathrm{sec}$. corresponds to a relatively rigid site. From figure 2, it is observed that for high period range, the spectra corresponding to a soft site have higher amplitudes as compared to the response spectra of a rigid site. The situation is reversed in the low period range where the response spectra of a rigid site become larger than that of the soft site. These observations are in full agreement with the results of seed et al (8).

\section{COMPARISIONS WITH OTHER SPECTRA}

In figures 3-8 site dependent smooth spectra are superimposed on the plots of spectra for actual earthquake records. These plots are taken directly from the Cal-Tech report (20) and the predominant site periods are estimated directly from these plots; (i.e. the site period is taken to be equal to the period which corresponds to the peak undamped response). The presently proposed smooth site dependent spectra are then constructed in accordance to the technique described in the previous section. The records considered here do show varieties in the peak ground acceleration and site periods (see Table 2). It should be noted here that the minimum damping coefficient for the proposed method is $0.5 \%$ while for the Cal-Tech plots this value is zero.

In all the figures $3-8$, the predicted smooth site dependent spectra provides relatively reasonable bounds on the corresponding actual response spectra curves. In certain cases and for some frequency ranges, the predicted response spectra over estimate the actual ones. For instance, the proposed spectra of Parkfield earthquake of 1966 as shown in figure 7 , are over-conservative for the large natural period range. Such over estimations which is on the conservative side is, of course, expected from the nature of smooth design spectra which are supposed to give the maximum response under any earthquake ground motions.

In figures 9 and 10 smooth site dependent spectra are compared with the Newmark spectra for damping coefficients of $0.5 \%$ and $5 \%$. In each case three site periods of $0.5,1$ and 1.5 seconds corresponding to relatively rigid, intermediate and relatively flexible sites are considered. It is observed that in certain period ranges the Newmark spectra is too conservative while in other period ranges it under estimates the spectra. From figure 9, it is observed that for flexible sites and small damping coefficients, the Newmark spectra underestimates the response spectra for all natural periods.

Similar comparisons are carried out with the Regulatory Guide 1.60 design response spectra in figures 11 and 12 for damping coefficients of $0.5 \%$ and $5 \%$. The conservativeness and under estimation of the R.G. 1.60 response spectra in various period ranges are apparent from figures 11 and 12 .

\section{FURTHER REMARKS}

A simplified procedure for the construction of smooth site dependent spectra based on the knowledge of the peak ground acceleration and the predominant site period is presented here. Some comparisons with actual spectra are also made and good agreements are observed. Furthermore, the smooth site dependent spectra for some relatively rigid, intermediate and relatively flexible sites are constructed and compared with the Newmark and R.G. 1.60 spectra and the possible deficiencies of these site independent design response spectra are pointed out.

\section{ACKNOWLEDGEMENTS}

The earlier stages of this study were carried out at the School of Engineering of Shiraz University, Shiraz, Iran and were supported by the Atomic Energy organization of Iran.

\section{REFERENCES}

1. Werner, S.D., "Procedures for developing vibratory ground motion criteria at nuclear plant sites" Nuclear Engineering and Design 36 (1976) 411-441. 


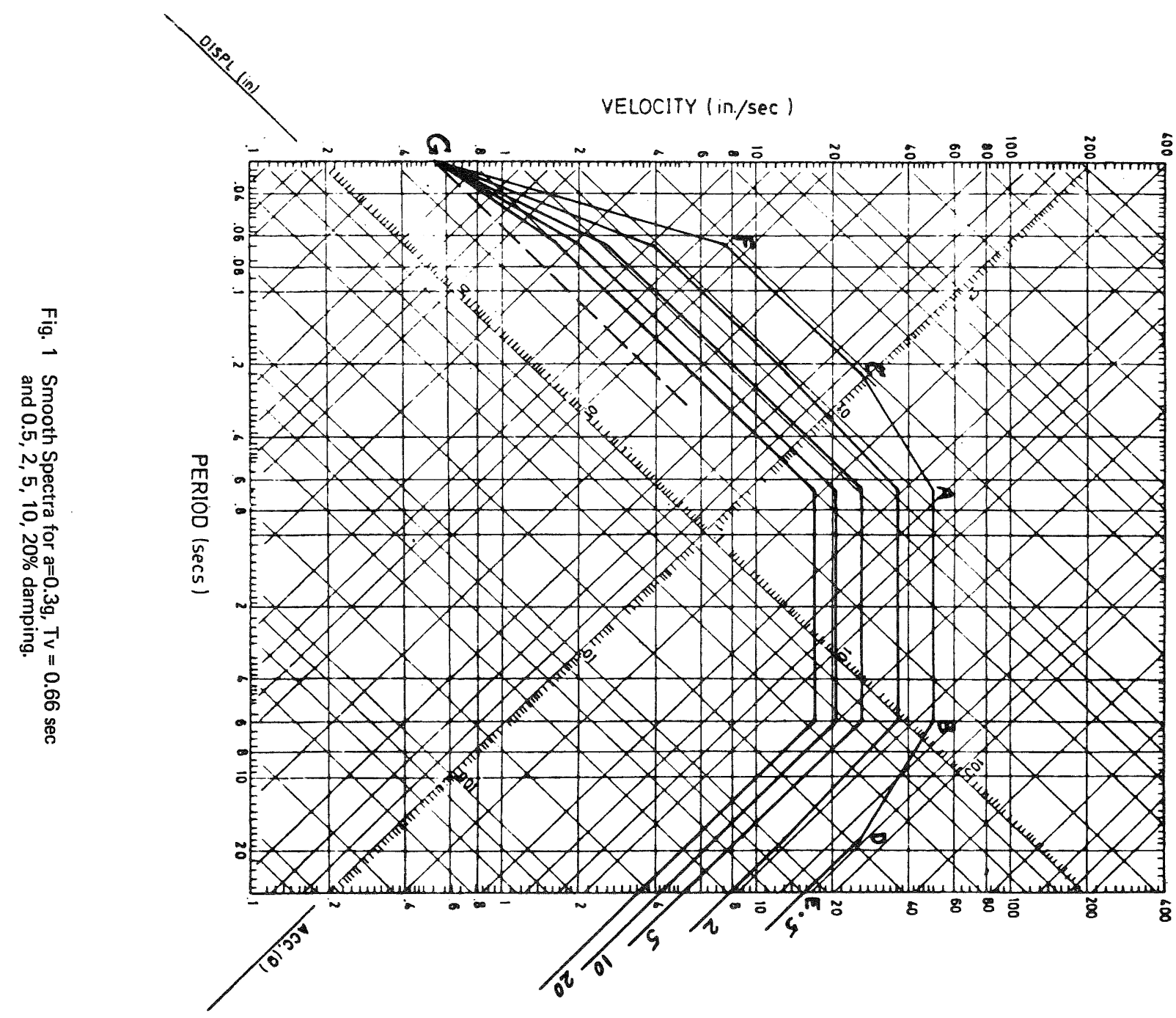

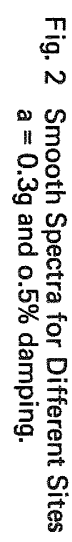

VELOCITY ( in./sec)

$2 / 8$
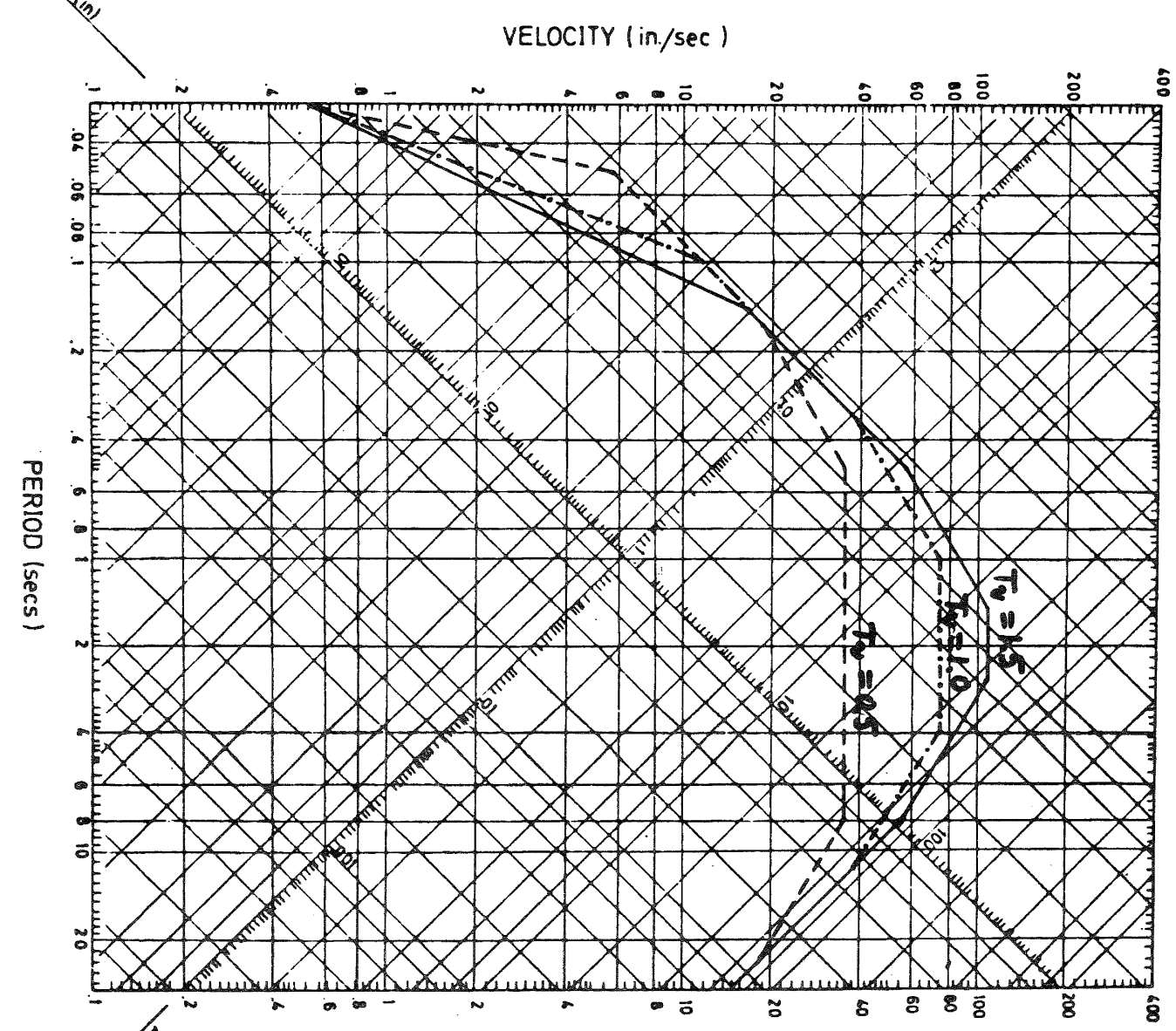

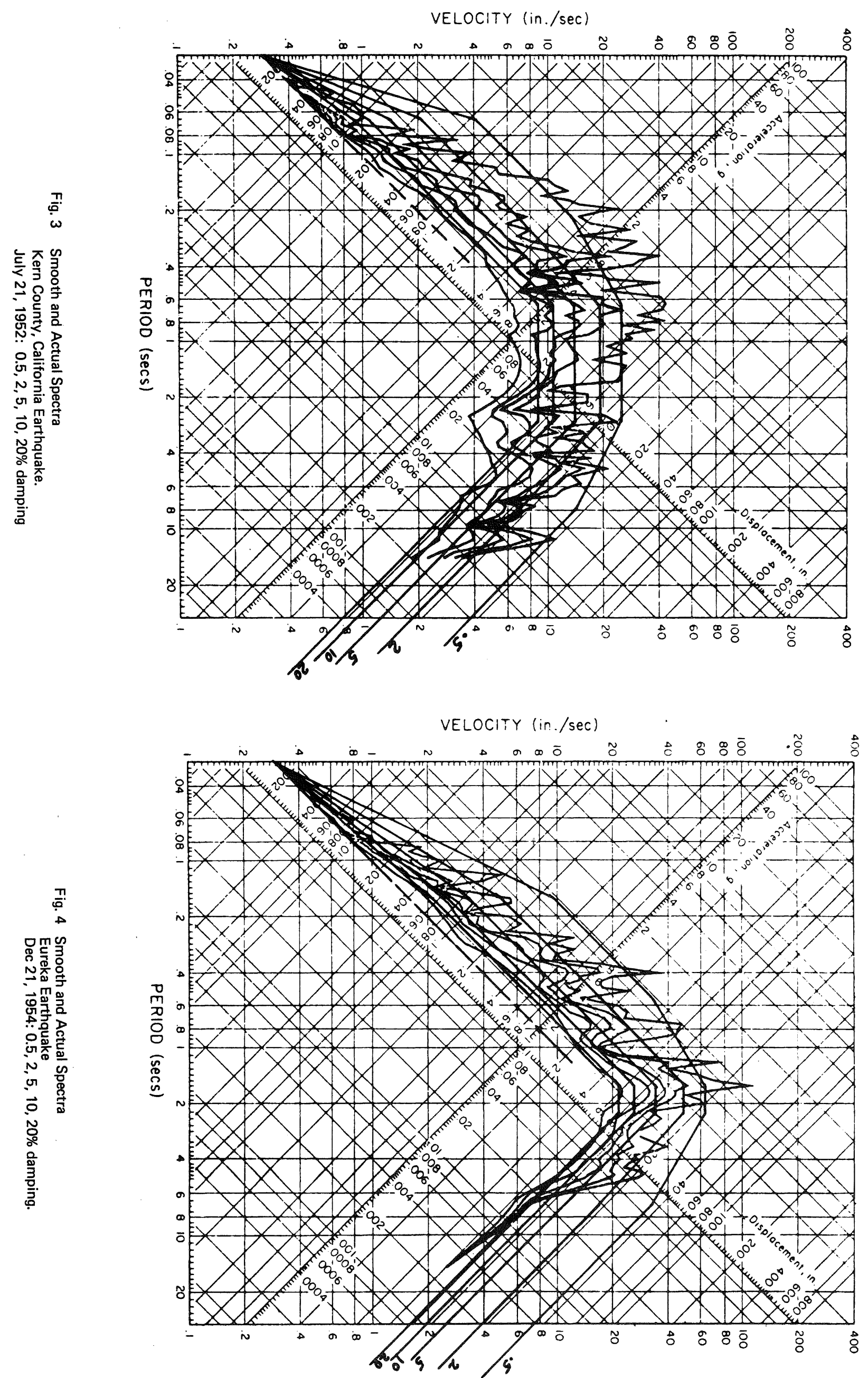


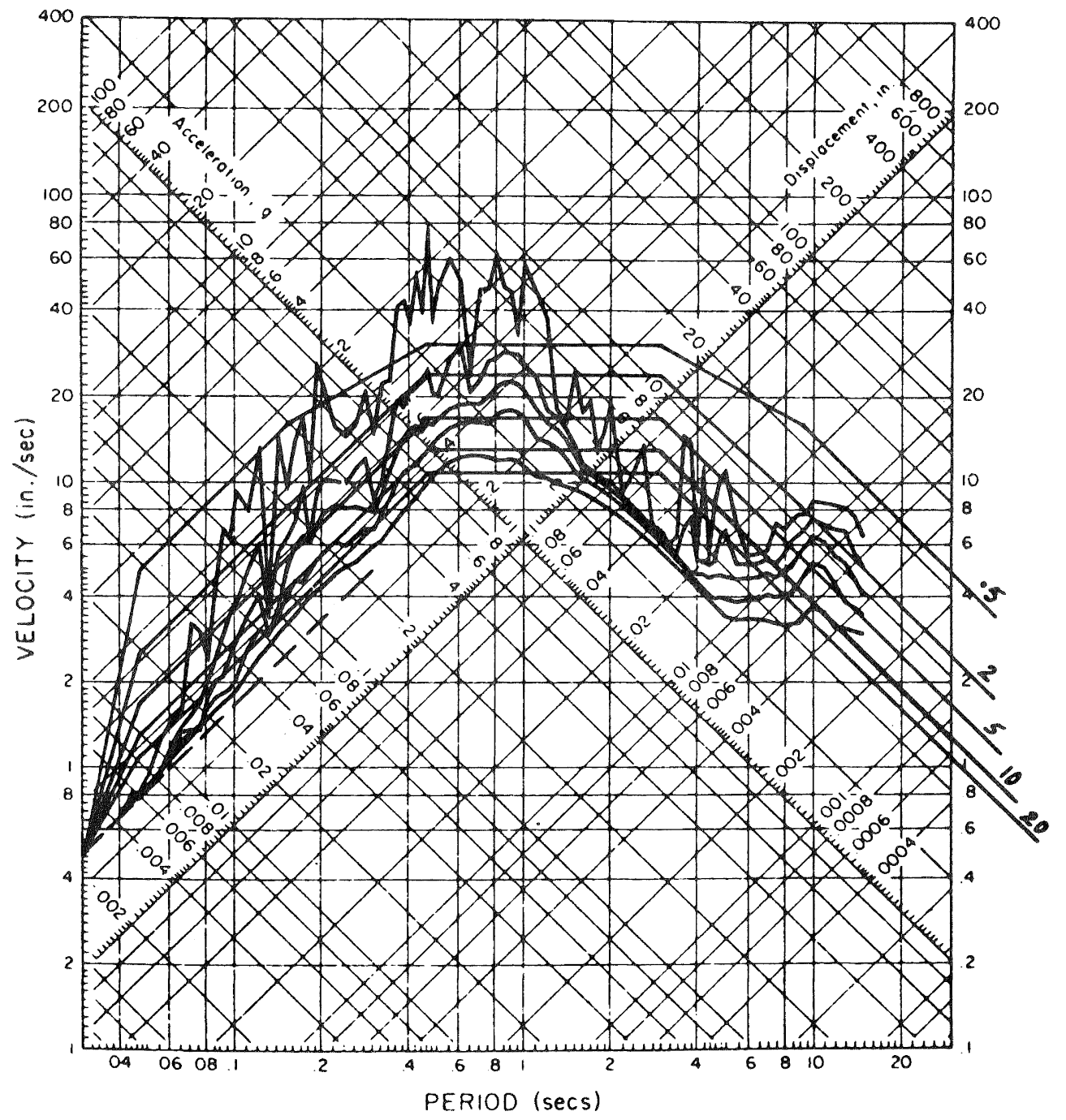

Fig. 5 Smooth and Actual Spectra

San Fernando Earthquake,
Feb 9, 1971: 0.5, 2, 5, 10, 20\% damping

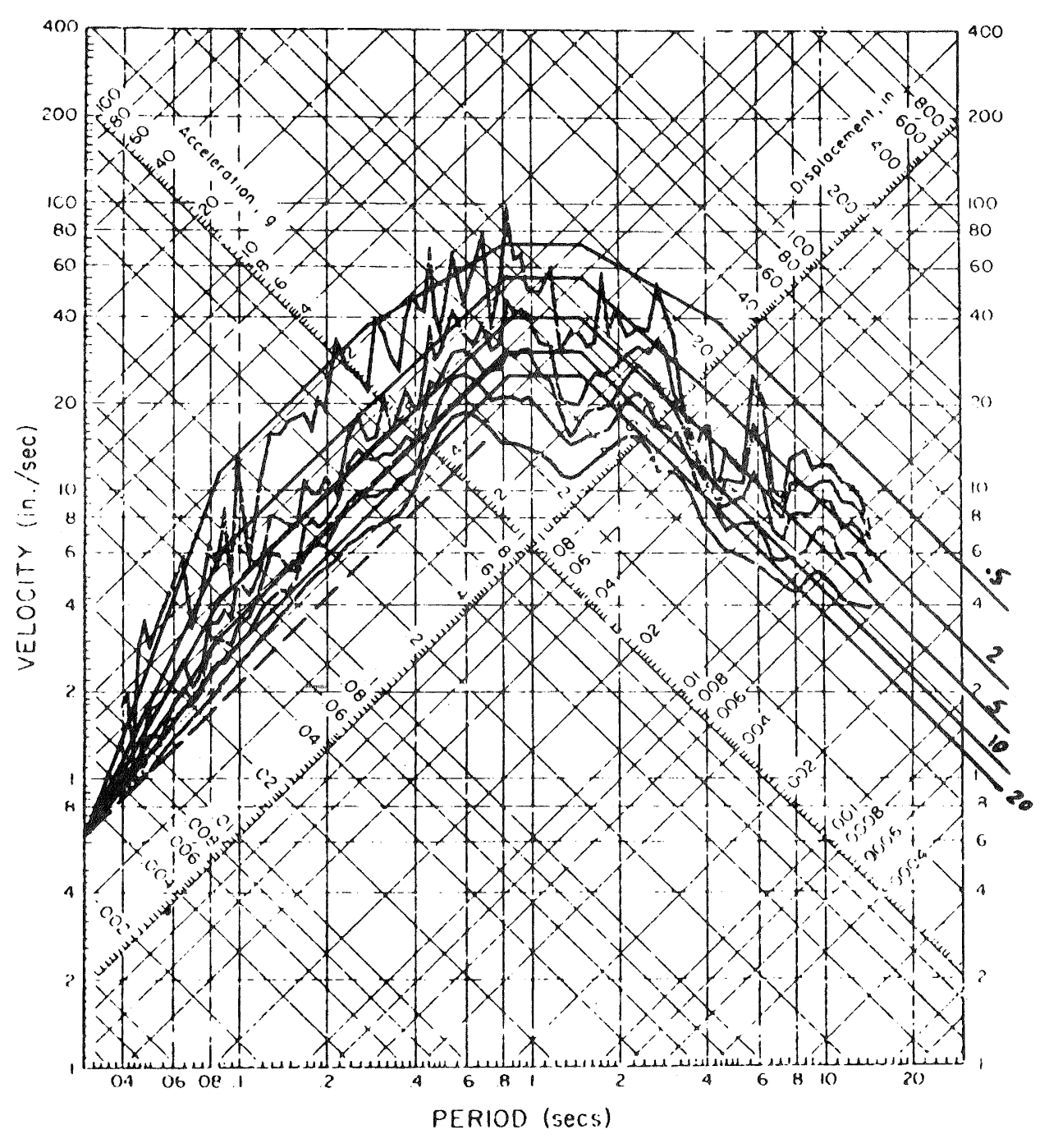

Fig. 6 Smooth and Actual Spectra

Imperial Valley Earthquake,
May 18, 1940: 0.5, 2, 5, 10, 20\% damping 


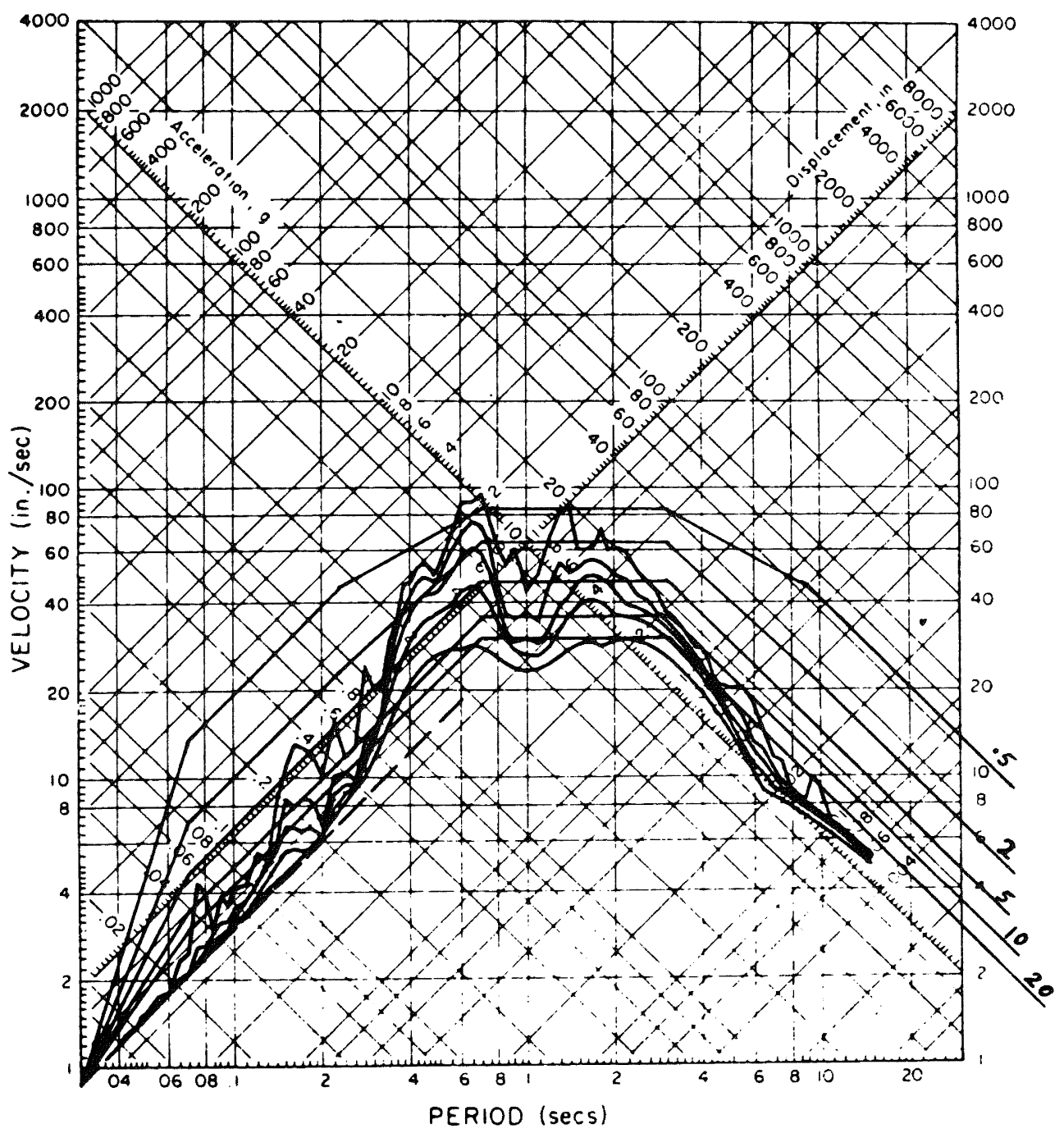

Fig. 7 Smooth and Actual Spectra

Parkfield, California Earthquake,

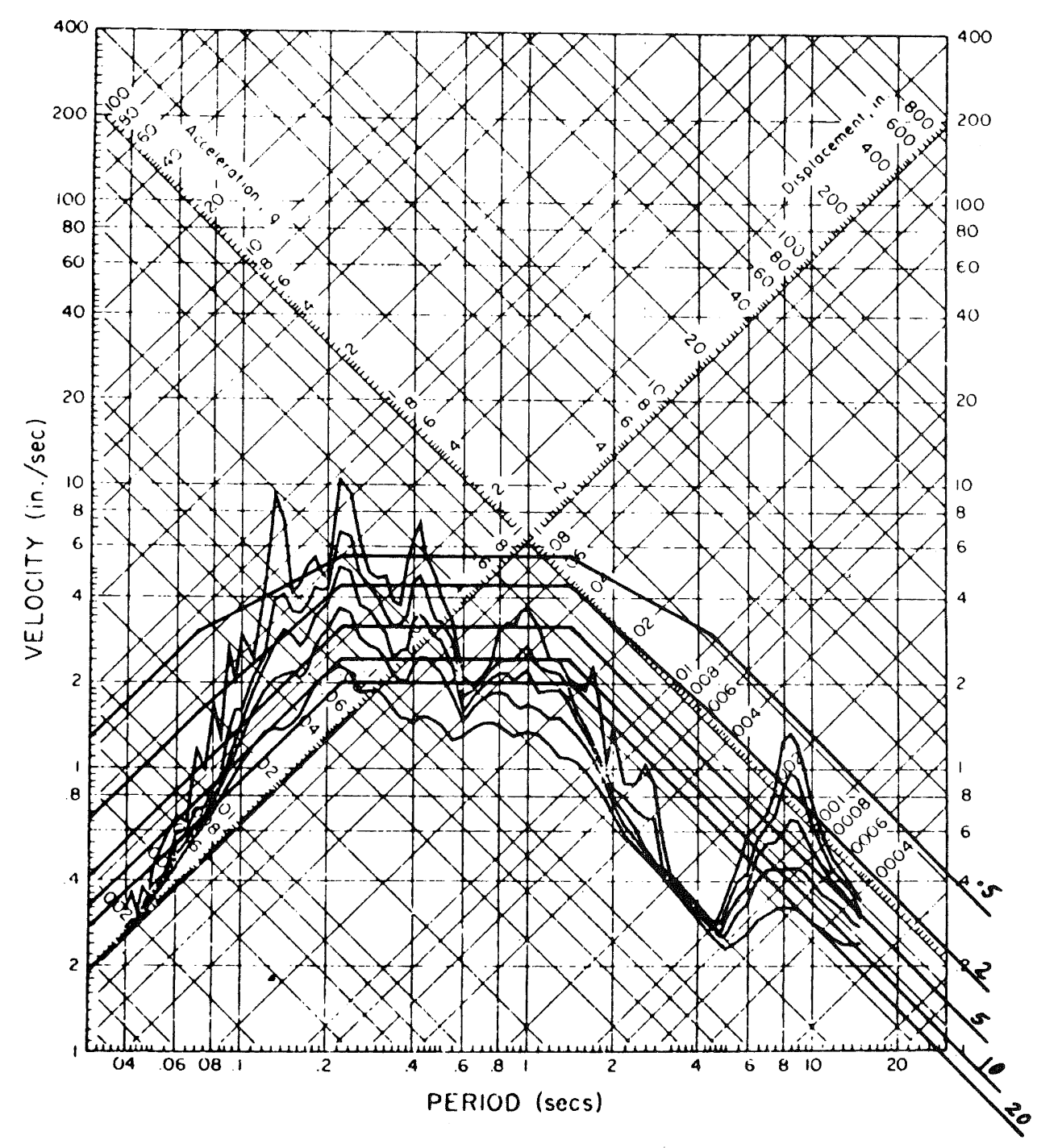

Fig. 8 Smooth and Actual Spectra

March 22, 1957: 0.5, 2, 5, 10, 20\% damping
Maran 

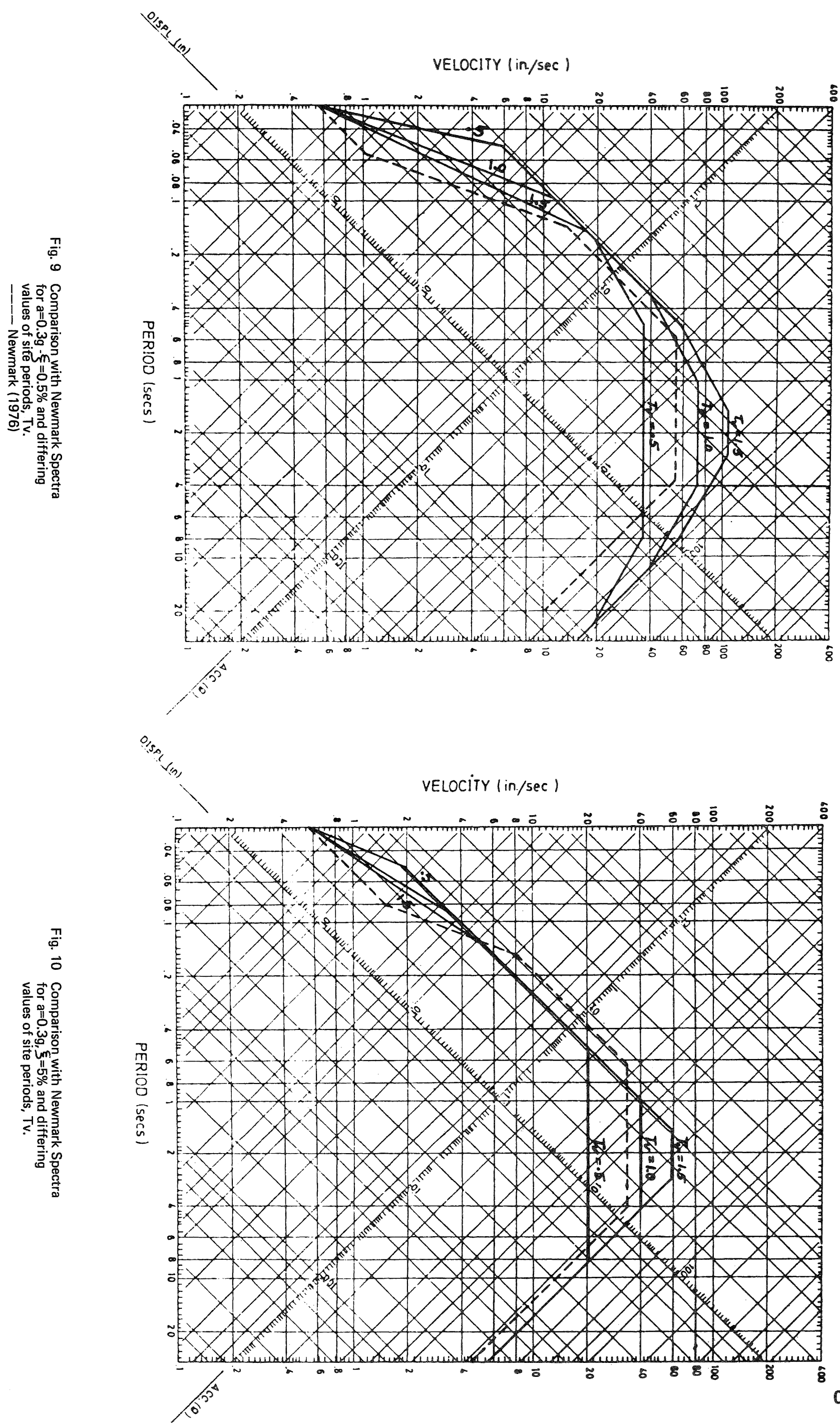


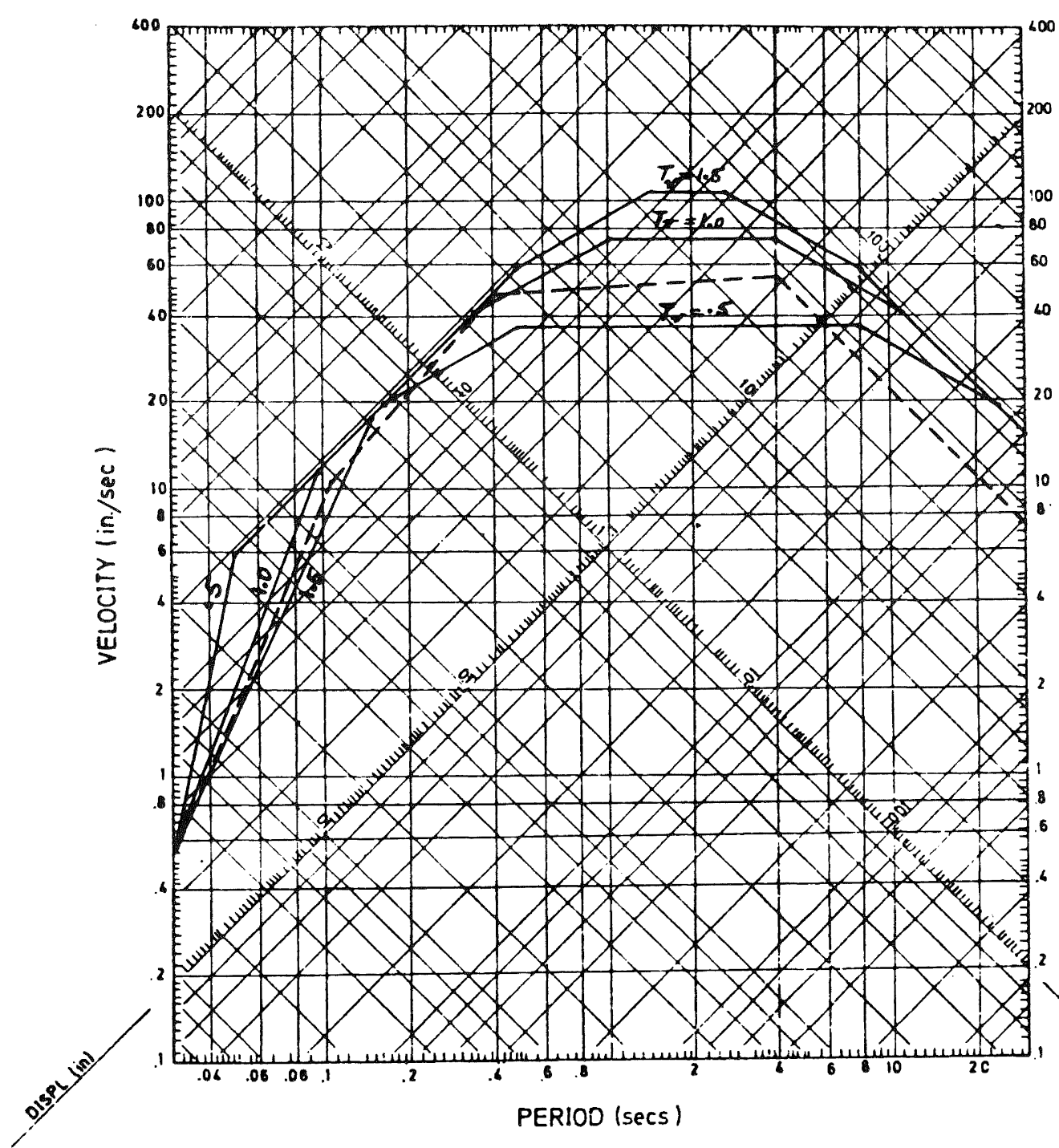

Fig. 11 Comparison with USNRC Spectra for $a=0.3 g, \xi=0.5 \%$ and differing values of site periods, Tv. -_- Regulatory Guide 1.60

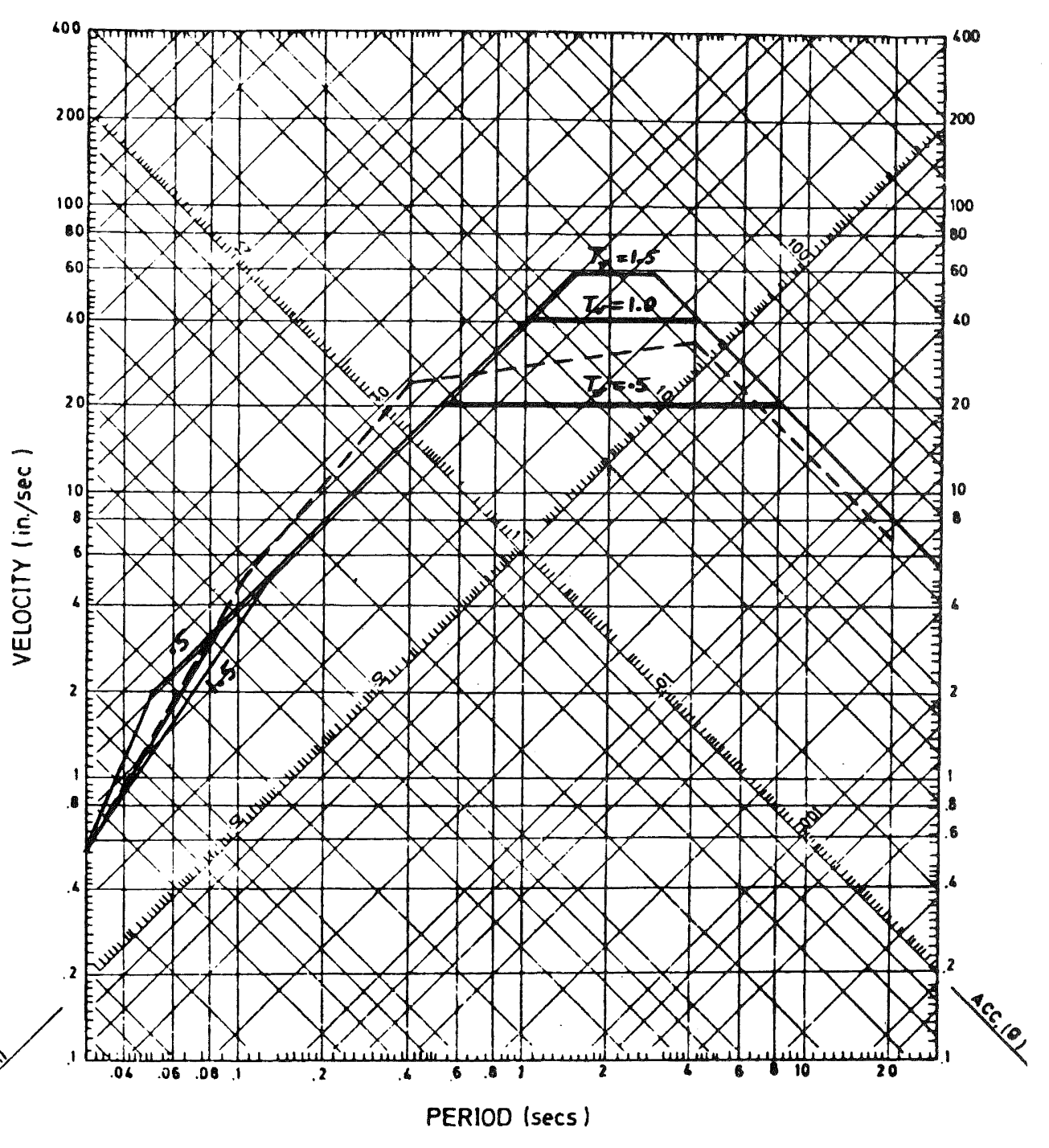

Fig. 12 Comparison with USNRC Spectra for $a=0.3 g, \xi=5 \%$ and differing value of site periods, $T V$. 
2. Housner, G.W., "Behaviour of Structures during Earthquakes", J. Eng. Mech. Div., Amer. Soc. Civ. Eng. 85 (EM4), Oct. (1959).

3. Newmark, N.M., Hall, W.J., "Seismic Design Criteria for Nuclear Reactor Facilities" "Proc. of the Fourth World Conference on Earthquake Engineering, Santiago, Chile (1969).

4. Mohraz, B., Hall, W.J., Newmark, N.M., "Study of Vertical and Horizontal Earthquake Spectra", Contract AT (49-5)-2667, Nathan M. Newmark Consulting Engineering Services, 114 Civil Engineering Building, Urbana, Illinois 61801, Dec. (1972).

5. Newmark, N.M., Blume, J.A., Kapure, K.K., "Seismic Design Spectra for Nuclear Power Plants", J. Power Div. Amer. Soc. Civ. Eng. 99(P02), Nov. (1973).

6. USAEC, "Design Response Spectra Plants", Regulatory Guide 1.60, Revision 1, Directorate of Regulatory Standards, Washington, D.C., Dec. (1973).

7. Hayashi, S., Tsuchida, H. Kurata, E., "Average Response Spectra for Various Subsoil conditions", Third Joint Meeting, U.S. Japan Panel on Wind and Seismic Effects, UJNR, Tokyo, (1971)

8. Seed, H.B., Ugas, G., Lysmer, J., "Site Dependent Spectra for Earthquake - Resistant Design, Earthquake Engineering Research Center, Report No. EERC 74-12, University of California, Berkeley, California, U.S.A. (1974).

10. Jennings, P.C. et al., "Simulated Earthquake motions for Design Purposes", Proc. of the Fourth World Conference on Earthquake Engineering, Santiago, Chile (1969). Comparison For Seismic Design of Nuclear Power

Table II - Actual Spectra Used for

11. Schnabel. P. et al., "Modifications of Seismograph Records for Effects of Local Soil Conditions", Bull. Seismol. Soc. Amer. 62(6), Dec. (1972).

12. Seed, H.B., Idriss, I.M., "Influence of Soil Conditions on Ground Ground Motions During Earthquake", J. Soil Mech. Found. Div., Amer. Soc. Civ. Eng. 95 (SMI), Jan. (1969).

13. Idriss, I.M., Seed, H.B., "Seismic Response of Horizontal Soil Layers", J. Soil Mech. Found. Div. Amer. Soc. Civ. Eng. 94 (SMA), July (1968).

14. Schnabel, P., Lysmer, J., "SHAKE, a computer program for earthquake response analysis of horizontally layered sites", EERC-72-12, University of California, Berkeley, California, U.S.A. (1972).

15. Tsai, N.C., Housner, G.W., "Calculation of Surface Motions of a Layered Half-Space" Bull. Seismol. Soc. Amer. 60(3), June (1970).

16. Lysmer, J., et al., "LUSH, A Computer program for complex response analysis of soil-structure systems", EERC

74-4, University of California, Berkeley, California, U.S.A. Apr. (1974).

17. Idriss, I.M." et al., "Seismic Response by Variable Damping Finite Elements", J. Geotech. Div. Amer. Soc. Civ. Eng. 100 (G T I), Jan. (1974).

18. Mostaghel, N., Ahmadi, G., "Smooth Site Dependent Spectra", Nuclear Engineering and Design 53(2), July (1979) pp. 263-300.

19. Newmark, N.M., Hall, W.J. "Earthquake Resistant Design of Nuclear Power Plants", Intergovernment Conference on Assessment and Mitigation of Earthquake Risk, UNESCO, Feb. 1976.

20. "Analyses of Strong Motion Earthquake Accelerograms", Volume III-Response Spectra, Parts A Through C, Earthquake Engineering Research Laboratory, California Institute of Technology, August $(1972 \ldots)$.

\begin{tabular}{|c|c|c|c|c|}
\hline Event & Mag. & Direct. & $\begin{array}{c}\text { Peak } \\
\text { ACC. } \\
\text { G. }\end{array}$ & $\begin{array}{l}\text { Pred. } \\
\text { Period } \\
\text { Sec. }\end{array}$ \\
\hline $\begin{array}{l}\text { Kern County, Calif. July 21, } 1952 \\
\text { Taft Lincoln School Tunnel }\end{array}$ & 7.7 & $\mathrm{~N} 21 \mathrm{E}$ & .156 & .65 \\
\hline $\begin{array}{l}\text { Eureka Earthquake Dec. 21, } 1945 \\
\text { Ferndale City Hall }\end{array}$ & 6.6 & N4 4E & .159 & 1.60 \\
\hline $\begin{array}{l}\text { San Fernando EQ, Feb. 9, } 1971 \\
\text { Castaic Old Ridge }\end{array}$ & 6.5 & $\mathrm{~N} 69 \mathrm{~W}$ & .270 & .46 \\
\hline $\begin{array}{l}\text { ElCentro Earthquake, May 18, } 1940 \\
\text { ElCentro Site }\end{array}$ & 6.3 & SOOE & .348 & .85 \\
\hline $\begin{array}{l}\text { Parkfield, Calif. EQ, June 27, } 1966 \\
\text { Cholame, Shandon Calif. Array No. } 2\end{array}$ & 5.6 & N65E & .489 & .70 \\
\hline $\begin{array}{l}\text { San Francisco EQ, Mar. 22, } 1957 \\
\text { Golden Gate Park }\end{array}$ & 5.3 & S80E & .105 & .22 \\
\hline
\end{tabular}

